\title{
Analysing Maltese Biology Examination Questions according to Cognitive Complexity
}

\author{
Carmel Azzopardi ${ }^{1}$ and Marthese Azzopardi ${ }^{2 *}$ \\ ${ }^{1}$ Department of Physics, University of Malta Junior College, Malta \\ ${ }^{2}$ Department of Biology, University of Malta Junior College, Malta
}

\begin{tabular}{l} 
ARTICLE INFO \\
\hline Keywords: \\
Biology \\
Bloom's revised \\
$\quad$ taxonomy \\
Cognitive objective \\
Examinations
\end{tabular}

\section{Introduction}

The majority of Maltese post-secondary students taking Biology at Advanced level aspire to work in medically-oriented positions. Irrespective of the degree they read for, the ability to analyse facts and make a reasoned judgment is fundamental not only to graduate, but above all in their profession. Various skills are required in critical thinking, including observation, analysis and evaluation. Steps in critical thinking were first described by a group of educational psychologists headed by Benjamin Bloom in 1956.

\begin{abstract}
This paper presents an analysis of Maltese Advanced Biology examination comprehension questions according to cognitive complexity. The research data consisted of 239 questions from 20 Summer examinations: 10 National and 10 at a public post-secondary Institution between 2010 and 2019. In this research, a qualitative approach and theory-driven content analysis method using Bloom's Revised Taxonomy of Cognitive Objectives were employed. The 121 Institution and 118 National examination questions were placed in two categories: higher-order cognitive skills (HOCS) comprising Remembering, Understanding and Applying and lower-order cognitive skills (LOCS) comprising Analysing, Evaluating and Creating on the basis of earlier research. Data was given with tables as percentage. This research was guided by the following two questions: What kinds of cognitive skills and knowledge do Maltese Advanced Biology comprehension examination questions require? What is the proportion of marks being awarded to the different cognitive levels? In the National examination questions were allocated to five of the cognitive categories while less, four, in the Institution. Over a 10-year period, the majority of the questions (91.6\% in Institution; $81.6 \%$ in National) required LOCS. In both types of examination, the highest percentage of questions were in the Remembering objective (53\% in Institution; $48 \%$ in National), followed by Understanding (31.84\% in Institution; $22 \%$ in National) and finally Applying (6\% in Institution; $11 \%$ in National). The study highlighted that the Analysing objective was absent in every comprehension and the Creating category was represented by a mere $1 \%$ in the National examination. The investigation was extended to determine the marks allocated to the different cognitive levels. The majority of the marks, $(92.0 \%$ in Institution; $81.7 \%$ in National examinations) belonged to the LOCS, being allocated mostly in the Remembering and Understanding objectives. The research indicates that the examinations were overall, not cognitively demanding, but the National one was more intellectually challenging for a number of reasons, including a larger percentage of questions and marks categorised as HOCS. The Bloom's Revised Taxonomy of Cognitive Objectives as used in this research gives a useful way for designing or analysing biology summative assessment tools. All three higher-order cognitive skills categories should be more evenly presented in future biology examinations.
\end{abstract}


Although Anderson et al., (2001) modified Bloom's taxonomy by changing the vocabulary, the underlying intent remains the same and is still widely used by educators to encourage critical thinking and learning in the classroom. Bloom's Revised Taxonomy was chosen as the theoretical framework for the present analysis because: (i) it is generic and can be applied to many subjects, (ii) easy to apply to a variety of question types due to its simple structure, (iii) widely recognisable and familiar to academics.

Zoller, 1993 explains that certain educators have simplified and combined the levels of cognitive domain into two categories: 'lower-order cognitive skills' (LOCS) and 'higherorder cognitive skills' (HOCS). The term LOCS is used for memorisation and recall that require only a minimum level of understanding and HOCS for the application of knowledge and critical thinking that require deep conceptual understanding. Karamustafaoglu et al., 2011 assert that when students engage in HOCS, they do not simply remember factual knowledge, but also use their knowledge for problem solving, analysing, and evaluating situations. It is such questions that reveal whether or not a student has truly grasped a concept. Tobias et al., 1995 are of the opinion that not at all exam questions must focus on high-level questions; but it is important to assess students' understanding on a wide range of cognitive levels.

Recently, much worldwide research regarding cognitive skills and knowledge has been done in the many subjects, including the field of biology education (e.g. Zheng et al., 2008; Cullinane \& Liston, 2016). Our review of the literature reveals one study based on the National data to describe the cognitive skills assessed in Advanced-level Biology but none at the post-secondary level examinations. Locally, Mercieca (2014) in her dissertation entitled 'Trends in Maltese Advanced Level biology from 1998 to 2011', determined the extent to which the National examination challenged the students intellectually. She analysed the percentages of low-order and high-order questions in the four papers in the May and September sittings. However, she did not review the questions according to the six categories according to Bloom's Revised Taxonomy.

The test questions are designed by a group of tutors at the post-secondary institution and by members of the National Examination Board on the basis of the goals and contents defined in the Curriculum. The National examination is highly valued and has a strong influence on both teaching and learning of biology in Maltese post-secondary schools. Therefore, it is very important to find a detailed answer to the following questions: What kinds of cognitive skills and knowledge do the biology tests of the Maltese examinations measure? What is the proportion of marks being awarded to the different cognitive levels? We noted that no investigations had been conducted on questioning techniques in Advanced biology comprehension questions. Keeping in mind the importance of such examinations in the preparation of future professionals in critical thinking, this study was performed to evaluate what kinds of cognitive skills and knowledge the National biology examinations measure (with respect to comprehension questions covered in Paper 2) and how they compare to those in a public Institution.

\subsection{Aims and Objectives}

The main objectives of this study were:

1. Classification of question types (i) over a 10-year period (2010-2019) and (ii) per year, using the Bloom's Revised Taxonomy of educational objectives-cognitive domain.

2. Determining the percentage of low- and high-order questions in Institution and National examinations (i) over a 10-year period (2010-2019) and (ii) per year.

3. Determining the percentage of marks allocated to each educational objectives-cognitive domain in the Bloom's Revised Taxonomy (i) over a 10-year period (2010-2019) and (ii) per year. 


\section{Materials \& Methods}

\subsection{Classifying the comprehension question types using Bloom's Revised Taxonomy}

This study focuses on the comprehension examination questions. Students are allocated one hour to answer such a question in both types of examination. Comprehensions from the 20 examination papers investigated carried a maximum of 25 marks, except that in the 2010 National examination which carried 20 marks. Analysis involved the following:

1. Classifying questions using Bloom's Revised Taxonomy of educational objectivescognitive domain.

2. Grouping questions into low- and high-order cognitive skills.

3. Comparing the percentage of marks allocated to each objective and the percentage of questions in each objective to investigate if question were awarded more marks as they progressed up the hierarchy.

The verbs in each question associated with each objective of the cognitive domain (Table 1) were classified according to Bloom's Revised Taxonomy. Individual questions in each comprehension were analysed and counted. If a question contained more than one part, each part was treated as a single question. For example, 'List TWO advantages and TWO risks that the application of genetically modified plants many have on the environment' (2016 National examination, Question 1.7) would have been treated as two questions from the remembering objective (verb: list). Sometimes a particular question had two parts from two different objectives as in 2015 Institution examination, Question (i): 'What theory is being referred to in the text as being one of life's prime inventions (line 29)? Briefly discuss THREE pieces of evidence that give support to this theory.' In this example, 'what' is from the remembering objective and discuss is from the understanding objective. Employing these methods, a total of 239 questions were analysed (121 Institution and 118 National).

As may be observed from Table 1, the six cognitive objectives may be collapsed into two groups: low- and high-order cognitive skills categories. In this investigation questions from the knowledge, comprehension and application were classified as low-order questions (LOQ) and those from the analysis, synthesis and evaluation levels, as high-order questions (HOQ).

Table 1.

Bloom's Revised Taxonomy of educational objectives: cognitive domain with associated verbs

\begin{tabular}{lll}
\hline \multicolumn{1}{c}{ Category } & \multicolumn{1}{c}{ Key verbs (keywords) } \\
\hline Low-order & $\begin{array}{l}\text { Remembering - } \\
\text { Retrieving relevant knowledge from long-term } \\
\text { memory. }\end{array}$ & $\begin{array}{l}\text { List, Locate, Name, Recognise } \\
\text { State, Describe, Recall, Repeat }\end{array}$ \\
$\begin{array}{l}\text { Understanding - } \\
\text { Determining the meaning of instructional messages, } \\
\text { including oral, written, and graphic communication. }\end{array}$ & $\begin{array}{l}\text { Conclude, Define in your own words, Illustrate, } \\
\text { Summarise, Categorise, Classify, Discuss, Match, } \\
\text { Sort, Explain }\end{array}$ \\
$\begin{array}{l}\text { Applying - } \\
\text { Carrying out or using a procedure in a given } \\
\text { situation. } \\
\text { Analysing - } \\
\text { Breaking material into its constituent parts and } \\
\text { detecting how the parts relate to one another and to } \\
\text { an overall structure or purpose. } \\
\text { Evaluating - } \\
\text { Making judgments based on criteria and standards. } \\
\text { Creating - } \\
\begin{array}{l}\text { Putting elements together to form a novel, coherent } \\
\text { whole or make an original product. }\end{array}\end{array}$ & Assess, Justify, Critique Judge \\
High-orderalise, Infer, Show, Select, Arrange, Organise, Outline \\
\hline
\end{tabular}


2.2. Comparing the percentage of marks allocated for each objective and the percentage of questions in each objective.

The marks allocated to each of the six objectives according to Bloom's Revised Taxonomy were counted. In the case of a question being composed of two parts, the marks were divided according to the mark schemes provided by the Institution. Since no mark schemes are published for the National examinations, marks were divided as deemed most appropriately. All marks were calculated as a percentage to allow comparison since the 2010 National examination question carried 20 marks, unlike the rest which carried 25 marks.

\section{Results}

3.1. Classifying the comprehension question types and marks using Bloom's Revised Taxonomy

Results presented in Figure 1 show that not all categories of Bloom's Revised Taxonomy were represented over the period 2010-2019. In the National examination, questions associated with comprehensions were allocated to five of the categories while less, four, at the Institution. The Analysing objective was missing from both examinations. The Creating objective was also lacking from the Institution examinations. According to Tobias et al., (1995), it is important to assess students' understanding on a wide range of cognitive levels. Hence, especially the Institution examination, is lacking in this respect. However, having specific categories missing has been reported in various studies such as that by Cullinane \& Liston (2016). The Creating and Evaluating objectives where missing from the Irish Leaving Certificate Biology examination papers between 19992008. The Creating objective was also missing in five introductory biology courses for undergraduates and basic science courses in medical schools investigated by Zheng et al., (2008) who analysed 586 questions. Mambwe (2017) found that Application, Analysis and Evaluation levels remained at $0 \%$ throughout the years in some of the reviewed Nursing examination question papers (2011 to 2013).

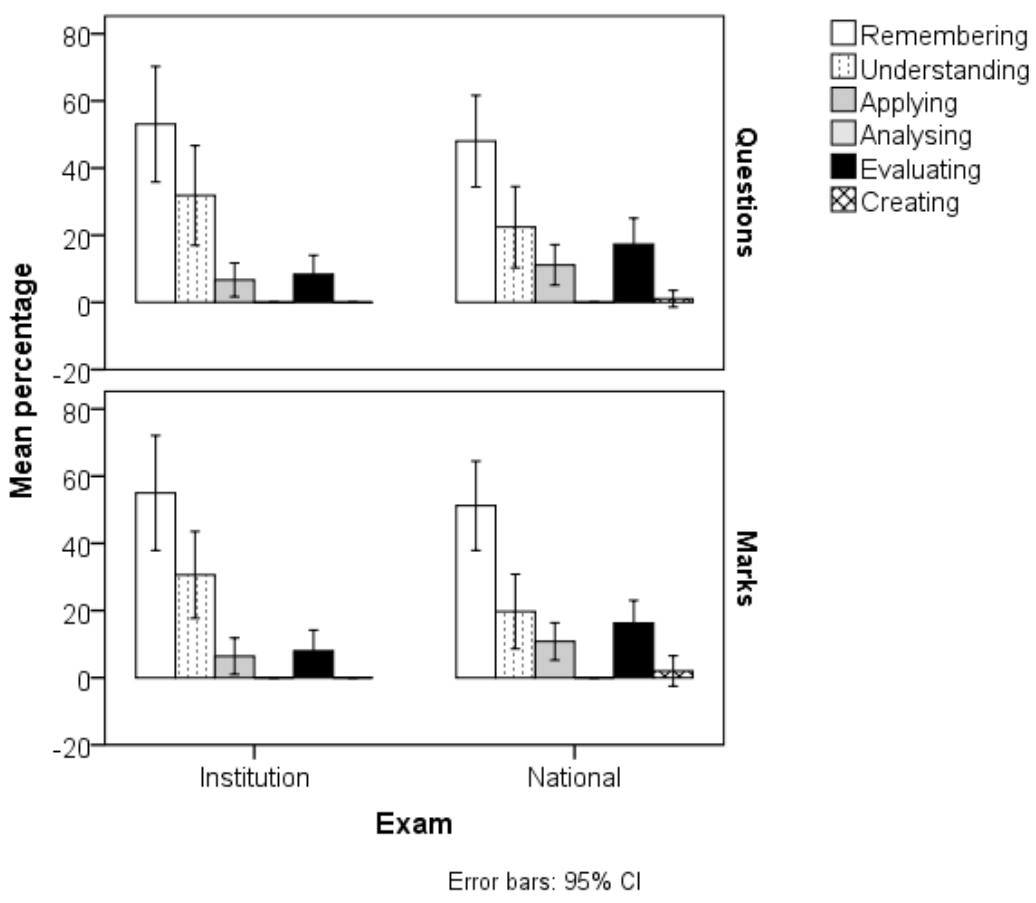

Figure 1: Graph showing the average percentages and $95 \%$ confidence intervals of questions and marks from Institution and National examinations (2010-2019), classified according to Bloom's Revised Taxonomy 
The percentage of marks for each objective in the cognitive domain was investigated in order to establish which type of question was rewarded in the exam. Figure 1 and Table 3 show that the Remembering objective received the highest percentage of marks in both examinations $55.0 \%$ in Institution; $51.2 \%$ in National). From Table 2, it is observed that a total of 238 questions, (121 Institution; 118 National) were analysed from past papers spanning over 2010-2019. The number of questions in the two examinations is comparable, however they differ in the type of cognitive category they were classified in. When investigating how many objective categories were represented per year, Figure 2 shows that the number was higher in National examinations. Questions from four categories were recorded in 7 out of 10 years, whereas fewer, 4 in Institution examinations. The least number of objective categories represented in any examination was two: 2013 and 2016 in Institution; 2015 in National examinations. Questions from only one category (Remembering) were present in each examination and their percentage dominated (Figure 2) in all 20 past papers analysed, reaching as high as $88.9 \%$ in both examination types. The next most commonly occurring cognitive objective was Understanding (Figure 2). It occurred in 85\% (17/20) of the papers investigated. Figure 2 also shows that in each year investigated, the percentage of marks allocated to each cognitive objective mirrors that of the questions.

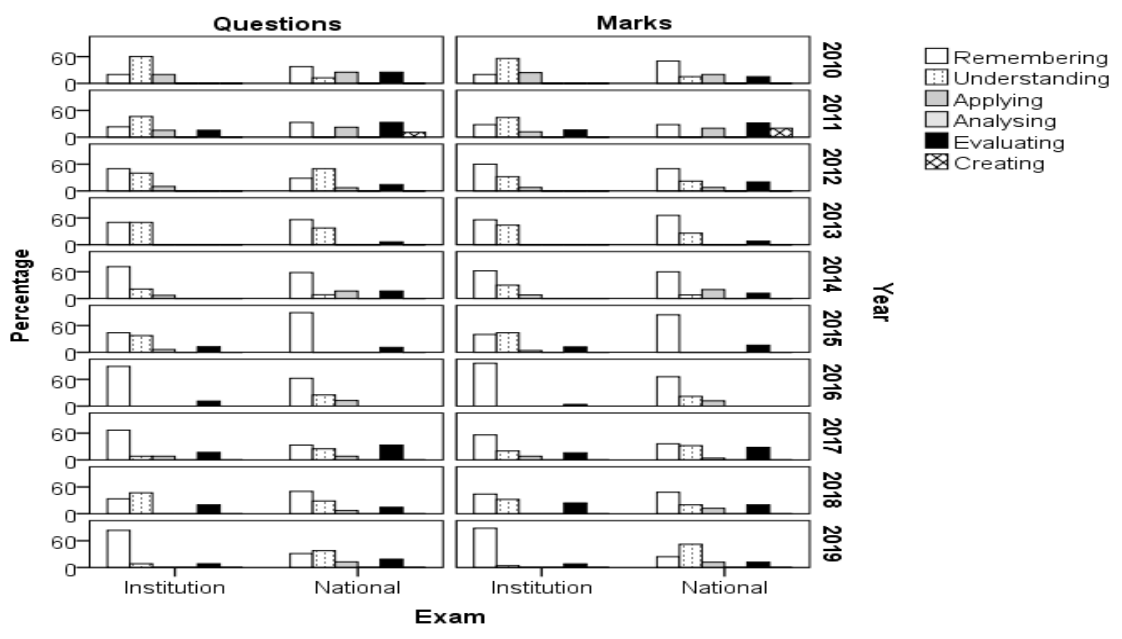

Figure 2: Graph showing the percentages of questions and marks from Institution and National examinations (2010-2019), classified according to Bloom's Revised Taxonomy

\subsection{LOCS and HOCS questions and marks over the period 2010-2019}

Table 3 and Figure 3 reveal that over the period 2010-2019, the majority of biology questions required low-order cognitive skills. A higher mean percentage $(91.60 \%)$ of such questions was recorded at the Institution examinations compared to the National (81.60\%) ones. According to Tsaparlis \& Zoller (2003), it is typical of most examination questions used in summative assessment to require only lower-order cognitive skills. Similarly, Zheng et al., (2008) who investigated the 1999 and 2002 Advanced Placement Biology exams found that they contained 120 lower-level questions worth $60 \%$ of the total score and four higher-level questions worth $40 \%$ of the total score.

The percentage of marks allocated to the Evaluating objective was $10 \%$ more in National papers with respect to those in the Institution. This is in line with findings in the literature. Jones et al., (2009) argue that academics cannot set an examination paper comprising numerous LOCQ (simple recall of information) when they must assess the acquired skills of final-year students. Similarly, first-year students cannot be expected to answer many HOCQ (evaluation of complex problems) in an examination paper, as they are still assimilating new information. On the other hand, Momsen et al., (2010) state that it is only through questions that aspire to higher cognitive domains that students will have the opportunity to hone and refine their skills while learning content within a meaningful context. 
Table 2.

Percentage of questions per cognitive objective in Institution (I) and National (N) examinations (LO: low-order; HO: high-order)

\begin{tabular}{ccccccccccc}
\hline Year & Exam & $\begin{array}{c}\text { Remember } \\
(\mathrm{LO})\end{array}$ & $\begin{array}{c}\text { Understand } \\
(\mathrm{LO})\end{array}$ & Apply (LO) & $\begin{array}{c}\text { Analyse } \\
(\mathrm{HO})\end{array}$ & $\begin{array}{c}\text { Evaluate } \\
(\mathrm{HO})\end{array}$ & $\begin{array}{c}\text { Create } \\
(\mathrm{HO})\end{array}$ & LO & HO & Total \\
\hline \multirow{2}{*}{2010} & $\mathrm{I}$ & 20.0 & 60.0 & 20.0 & 0.0 & 0.0 & 0.0 & 100.0 & 0.0 & 10 \\
& $\mathrm{~N}$ & 37.5 & 12.5 & 25.0 & 0.0 & 25.0 & 0.0 & 75.0 & 25.0 & 8 \\
2011 & $\mathrm{I}$ & 23.1 & 46.2 & 15.4 & 0.0 & 15.4 & 0.0 & 84.6 & 15.4 & 13 \\
& $\mathrm{~N}$ & 33.3 & 0.0 & 22.2 & 0.0 & 33.3 & 11.1 & 55.6 & 44.4 & 9 \\
2012 & $\mathrm{I}$ & 50.0 & 40.0 & 10.0 & 0.0 & 0.0 & 0.0 & 100.0 & 0.0 & 10 \\
& $\mathrm{~N}$ & 28.6 & 50.0 & 7.1 & 0.0 & 14.3 & 0.0 & 85.7 & 14.3 & 14 \\
2013 & $\mathrm{I}$ & 50.0 & 50.0 & 0.0 & 0.0 & 0.0 & 0.0 & 100.0 & 0.0 & 10 \\
& $\mathrm{~N}$ & 56.3 & 37.5 & 0.0 & 0.0 & 6.3 & 0.0 & 93.8 & 6.3 & 16 \\
2014 & $\mathrm{I}$ & 71.4 & 21.4 & 7.1 & 0.0 & 0.0 & 0.0 & 100.0 & 0.0 & 14 \\
& $\mathrm{~N}$ & 58.3 & 8.3 & 16.7 & 0.0 & 16.7 & 0.0 & 83.3 & 16.7 & 12 \\
2015 & $\mathrm{I}$ & 43.8 & 37.5 & 6.3 & 0.0 & 12.5 & 0.0 & 87.5 & 12.5 & 16 \\
& $\mathrm{~N}$ & 88.9 & 0.0 & 0.0 & 0.0 & 11.1 & 0.0 & 88.9 & 11.1 & 9 \\
2016 & $\mathrm{I}$ & 88.9 & 0.0 & 0.0 & 0.0 & 11.1 & 0.0 & 88.9 & 11.1 & 9 \\
& $\mathrm{~N}$ & 62.5 & 25.0 & 12.5 & 0.0 & 0.0 & 0.0 & 100.0 & 0.0 & 8 \\
2017 & $\mathrm{I}$ & 66.7 & 8.3 & 8.3 & 0.0 & 16.7 & 0.0 & 83.3 & 16.7 & 12 \\
& $\mathrm{~N}$ & 33.3 & 25.0 & 8.3 & 0.0 & 33.3 & 0.0 & 66.7 & 33.3 & 12 \\
& $\mathrm{I}$ & 33.3 & 46.7 & 0.0 & 0.0 & 20.0 & 0.0 & 80.0 & 20.0 & 15 \\
& $\mathrm{~N}$ & 50.0 & 28.6 & 7.1 & 0.0 & 14.3 & 0.0 & 85.7 & 14.3 & 14 \\
& $\mathrm{I}$ & 83.3 & 8.3 & 0.0 & 0.0 & 8.3 & 0.0 & 91.7 & 8.3 & 12 \\
& $\mathrm{~N}$ & 31.3 & 37.5 & 12.5 & 0.0 & 18.8 & 0.0 & 81.3 & 18.8 & 16 \\
\hline
\end{tabular}

From Table 3, it transpires that the mean percentage of high-order questions $(18.42 \%)$ as well as marks (18.30\%) in the National examination amount to more than double of those at the Institution (8.40\% Questions; $8.00 \%$ Marks). In both examination types, the mean percentage of marks allocated to the high-order objectives is practically the same as that of the questions. This means that the few high-order questions carried few marks.

Table 3.

Mean percentage and standard deviation $(S D)$ of questions $(Q)$ and marks $(M)$ per cognitive objective in Institution and National examinations (2010-2019). (LO: low-order; HO: high-order)

\begin{tabular}{lccccc}
\hline \multirow{2}{*}{ Category } & \multirow{2}{*}{ Percentage } & \multicolumn{2}{c}{ Institution } & \multicolumn{2}{c}{ National } \\
\cline { 3 - 6 } & & Mean & SD & Mean & SD \\
\hline \multirow{2}{*}{ Remembering } & $\mathrm{Q}$ & 53.05 & 24.05 & 48.00 & 19.03 \\
\multirow{3}{*}{ Understanding } & $\mathrm{M}$ & 55.00 & 23.91 & 51.20 & 18.60 \\
& $\mathrm{Q}$ & 31.84 & 20.76 & 22.44 & 16.90 \\
Applying & $\mathrm{M}$ & 30.60 & 18.09 & 19.7 & 15.56 \\
& $\mathrm{Q}$ & 6.71 & 7.04 & 11.14 & 8.42 \\
Analysing & $\mathrm{M}$ & 8.00 & 8.64 & 10.80 & 7.79 \\
& $\mathrm{Q}$ & - & - & - & - \\
Evaluating & $\mathrm{M}$ & - & - & - & - \\
& $\mathrm{Q}$ & 8.40 & 7.88 & 17.31 & 10.80 \\
Creating & $\mathrm{M}$ & 8.00 & 8.64 & 16.30 & 9.33 \\
& $\mathrm{Q}$ & - & - & 1.11 & 3.51 \\
Low-order & $\mathrm{M}$ & - & - & 2.00 & 6.32 \\
& $\mathrm{Q}$ & 91.60 & 7.88 & 81.60 & 12.99 \\
High-order & $\mathrm{M}$ & 92.00 & 8.64 & 81.70 & 14.03 \\
& $\mathrm{Q}$ & 8.40 & 7.88 & 18.42 & 12.98 \\
& $\mathrm{M}$ & 8.00 & 8.64 & 18.30 & 14.03 \\
\hline
\end{tabular}




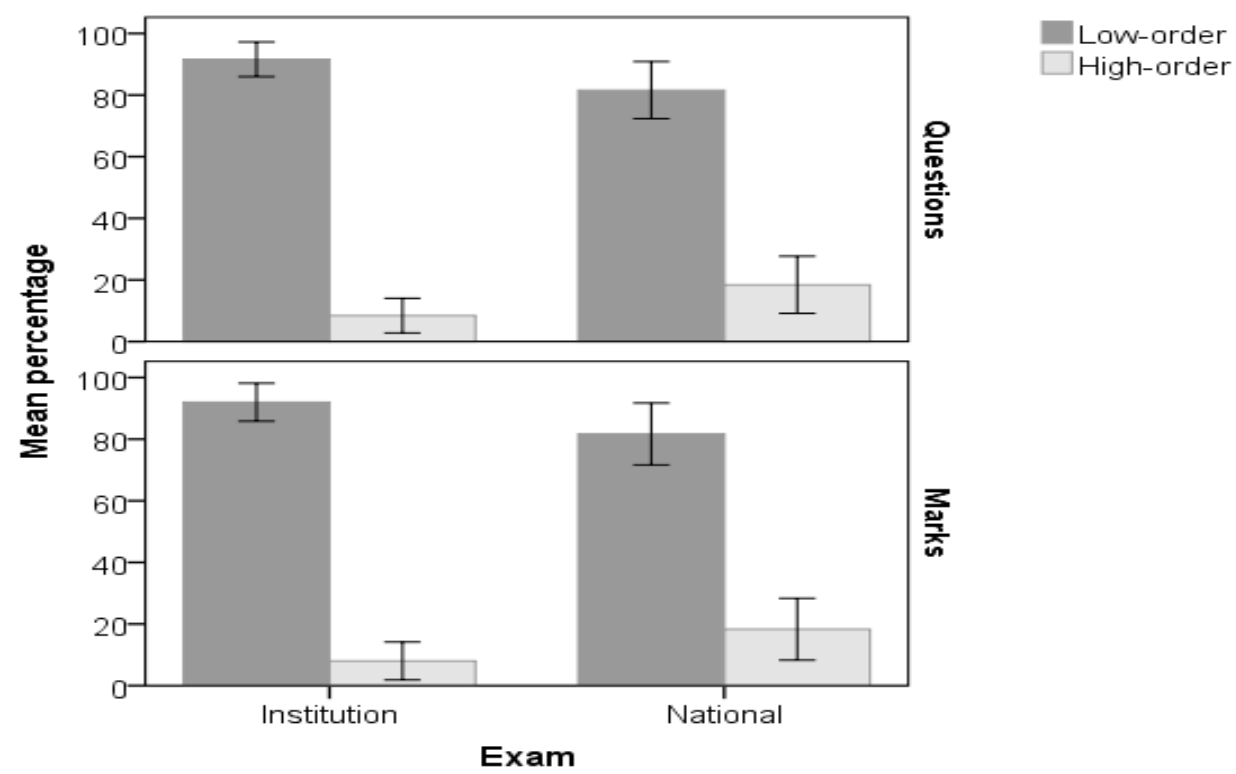

Figure 3: Graph showing the mean percentage of questions and marks allocated to low-order and high-order cognitive skills in Institution and National examinations (2010-2019)

Table 4.

The percentage of marks per cognitive objective in Institution (I) and National $(N)$ examinations. (LO: low-order; HO: high-order)

\begin{tabular}{|c|c|c|c|c|c|c|c|c|c|}
\hline Year & Exam & $\begin{array}{c}\text { Remembering } \\
\text { (LO) }\end{array}$ & $\begin{array}{c}\text { Understanding } \\
\text { (LO) }\end{array}$ & $\begin{array}{l}\text { Applying } \\
\text { (LO) }\end{array}$ & $\begin{array}{l}\text { Analysing } \\
(\mathrm{HO})\end{array}$ & $\begin{array}{c}\text { Evaluating } \\
(\mathrm{HO})\end{array}$ & $\begin{array}{c}\text { Creating } \\
(\mathrm{HO})\end{array}$ & LO & $\mathrm{HO}$ \\
\hline \multirow{2}{*}{2010} & I & 20 & 56 & 24 & 0 & 0 & 0 & 100 & 0 \\
\hline & $\mathrm{N}$ & 50 & 15 & 20 & 0 & 15 & 0 & 85 & 15 \\
\hline \multirow{2}{*}{2011} & I & 28 & 44 & 12 & 0 & 16 & 0 & 84 & 16 \\
\hline & $\mathrm{N}$ & 28 & 0 & 20 & 0 & 32 & 20 & 48 & 52 \\
\hline \multirow{2}{*}{2012} & I & 60 & 32 & 8 & 0 & 0 & 0 & 100 & 0 \\
\hline & $\mathrm{N}$ & 30 & 42 & 8 & 0 & 20 & 0 & 80 & 20 \\
\hline \multirow{2}{*}{2013} & I & 56 & 44 & 0 & 0 & 0 & 0 & 100 & 0 \\
\hline & $\mathrm{N}$ & 66 & 26 & 0 & 0 & 8 & 0 & 92 & 8 \\
\hline \multirow{2}{*}{2014} & I & 62 & 30 & 8 & 0 & 0 & 0 & 100 & 0 \\
\hline & $\mathrm{N}$ & 60 & 8 & 20 & 0 & 12 & 0 & 88 & 12 \\
\hline \multirow{2}{*}{2015} & I & 84 & 0 & 0 & 0 & 16 & 0 & 84 & 16 \\
\hline & $\mathrm{N}$ & 40 & 44 & 4 & 0 & 12 & 0 & 88 & 12 \\
\hline \multirow{2}{*}{2016} & I & 96 & 0 & 0 & 0 & 4 & 0 & 96 & 4 \\
\hline & $\mathrm{N}$ & 66 & 22 & 12 & 0 & 0 & 0 & 100 & 0 \\
\hline \multirow{2}{*}{2017} & I & 56 & 20 & 8 & 0 & 16 & 0 & 84 & 16 \\
\hline & $\mathrm{N}$ & 36 & 32 & 4 & 0 & 28 & 0 & 72 & 28 \\
\hline \multirow{2}{*}{2018} & I & 44 & 32 & 0 & 0 & 24 & 0 & 76 & 24 \\
\hline & $\mathrm{N}$ & 48 & 20 & 12 & 0 & 20 & 0 & 80 & 20 \\
\hline \multirow{2}{*}{2019} & I & 22 & 1 & 0 & 0 & 2 & 0 & 23 & 2 \\
\hline & $\mathrm{N}$ & 24 & 52 & 12 & 0 & 12 & 0 & 88 & 12 \\
\hline
\end{tabular}




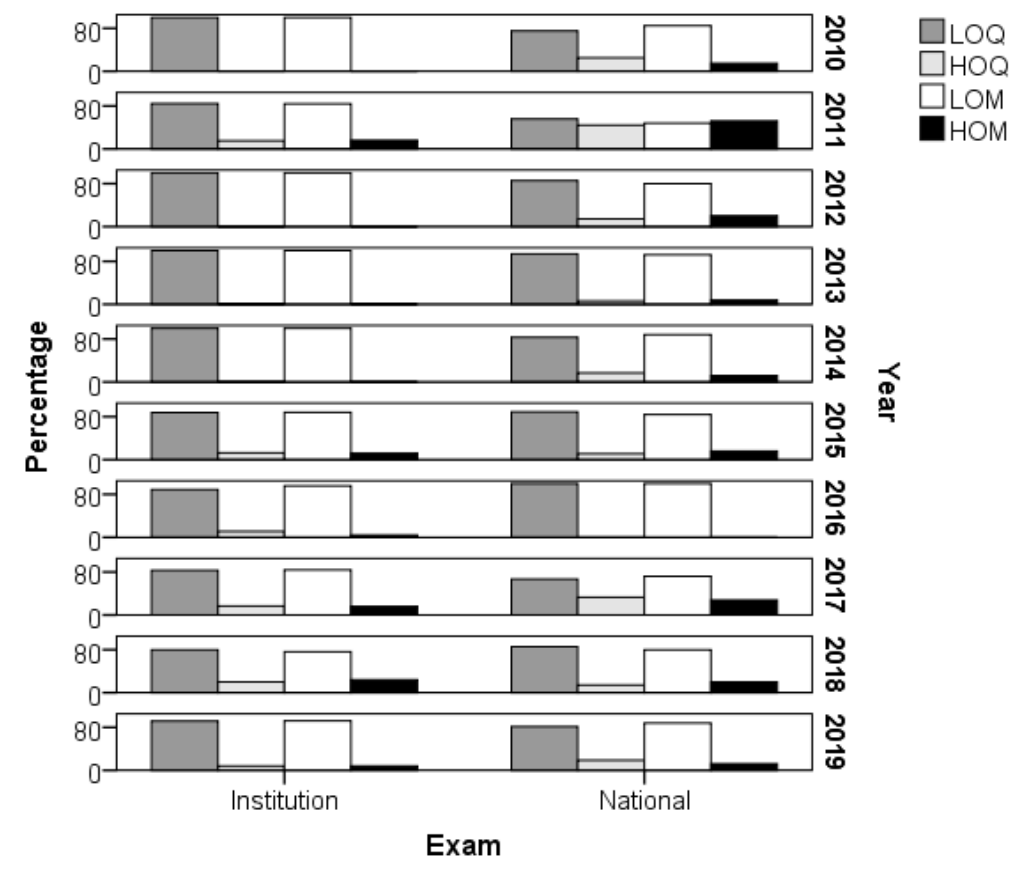

Figure 4: Graph showing the percentage of questions (Q) and marks (M) allocated to low-order (LO) and high-order (HO) cognitive objectives in Institution and National examinations (2010-2019)

Another result in this investigation involves a comparison between the percentage of questions and marks rewarded per year (Figure 4). This figure highlights the imbalance between the percentage of questions and marks between the low-order and high-order objectives. A high percentage of low-order questions accompanied by an equally high percentage of marks and vice versa was the trend observed in each comprehension except in the 2011 National examinations. In this unique situation, the percentage of marks allocated to high-order questions not only was the highest recorded (52\%), but exceeded that of the marks rewarded to low order questions.

The final point in this investigation involves a comment on the number of questions presented in each comprehension. A large number of questions asked per comprehension may be a factor that leads to unfair examinations. To illustrate this, in 2017 (Table 2), the comprehension consisted of 12 parts and it is also relevant to note that a substantial percentage of them, $(33.3 \%)$, were high-order questions. In 2011 an even higher percentage was recorded $(44.4 \% ; 4 / 9)$. If these percentages are evaluated in the light of the National Syllabus that requires a minimum of $25 \%$ of the marks of the overall examination to be dedicated towards high-order questions, then a single item carries excessive weight. The length of the comprehension passage also contributes to fairness. In her dissertation entitled 'Trends in Maltese Advanced Level biology from 1998 to 2011', Mercieca (2014) interviewed lecturers about their impressions of the National examination. She reported that some respondents found that comprehensions were too long to read and hence, these were perceived as unfair. She proceeds to mention that a particular interviewee argued that, due to having long comprehensions, students could not finish the essays.

\section{Conclusion}

Bloom's Revised Taxonomy was used as a tool to make comparisons between comprehension questions at a post-secondary Institution and the National examinations. Results showed that not all of the six cognitive categories were represented. The National examination lacked the Analysing objective while the Institution also lacked questions at the Creating objective. The study highlighted that the majority of comprehension questions and marks in both 
examinations, belonged to the LOCS, and were mostly attributed to the Remembering and Understanding objectives. This result may be justified by saying that when examiners format questions they keep in mind that students at the Institution have less experience in the subject and more attention is given to testing the knowledge rather than the reasoning component. Indeed, Guo (2008) says that for introductory college science courses, many educators argue that a primary focus on knowledge and comprehension is necessary before students can complete higher-level thinking tasks. However, there is no evidence to support such claims (Momsen et al., 2010). Finally, it may be concluded that comprehension questions in local examinations do not promote critical thinking.

\subsection{Pedagogical Implications}

When formulating comprehension questions attention should be given to:

1. Including as much of the cognitive categories as possible;

2. Increasing the proportion of high-order cognitive skills;

3. Keeping a balance between the overall number of questions and those being higher-order to allow ample time for reasoning.

\section{References}

Anderson, L. W., Krathwohl, D. R., Airasian, P. W., Cruikshank, K. A., Mayer, R. E., Pintrich, P. R., Raths, J. and Wittrock, M. C. (2001). A Taxonomy for Learning, Teaching, and Assessing: A revision of Bloom's Taxonomy of Educational Objectives. New York: Pearson, Allyn \& Bacon.

Guo, S. S. (2008). Science education: Should facts come first? Science 320, 1012.

Jones, K. O., Harland, J., Reid, J. M. V. and Bartlett, R. (2009). Relationship between examination questions and bloom's taxonomy. Proceedings - Frontiers in Education Conference. 1 - 6. https://doi.org/10.1109/fie.2009.5350598

Cullinane, A. and Liston, D. (2016). Review of the Leaving Certificate biology examination papers (1999-2008) using Bloom's taxonomy - an investigation of the cognitive demands of the examination, Irish Educational Studies, 35:3, 249-267. https://doi.org/10.1080/03323315.2016.1192480

Karamustafaoglu, S., Karamustafaoğlu, O., Ahmet, B. and Salih, B. (2011). Classification of biology exam questions as to bloom. Energy Education Science and Technology Part B: Social and Educational Studies. 3. 579-588.

Mambwe, P. (2017). Knowledge of Bloom's Hierarchy of Cognitive Levels of Educational Objectives and its use in Setting Examinations by Nurse Educators in Lusaka and Eastern Provinces. Texila International Journal of Nursing Volume 3, Issue 2. https://doi.org/10.21522/tijnr.2015.03.02.art008

Mercieca, L. (2014). Trends in MATSEC Advanced Level Biology From 1998 To 2011. Unpublished dissertation Presented to the Faculty of Education in Part Fulfilment of the Requirements for the Degree of Bachelor in Education (Honours) at the University of Malta. 398pp.

Momsen, J. L., Long, T. M., Wyse, S. A. and Ebert-May, D. (2010). Just the facts? Introductory undergraduate biology courses focus on low-level cognitive skills. CBE life sciences education, 9(4). https://doi.org/10.1187/cbe.10-01-0001

Tobias, S. and Raphael, J. (1995). In-class examinations in college science-new theory, new practice. J Coll Sci Teac; 24:242-244. 
Tsaparlis, G. and Zoller, U. (2003). Evaluation of higher vs. lower-order cognitive skills-type examinations in chemistry: implications for university in-class assessment and examinations. University Chemistry Education, 7(2), pp. 50-57.

Zheng, A. Y., Lawhorn, J. K., Lumley, T. and Freeman, S. (2008). Application of Bloom's Taxonomy Debunks the "MCAT Myth". Science, 319, 414-415. https://doi.org/10.1126/science.1147852

Zoller, U. (1993). Are lecturing and learning compatible? Maybe for LOCS: Unlikely for HOCS. J. Chem Educ; 70:195-197. https://doi.org/10.1021/ed070p195 